\title{
ANALISA PERBANDINGAN PENGARUH BAURAN PEMASARAN PRODUK PELUMAS MEREK GLOBAL DAN MEREK GLOBAL TERHADAP KEPUASAN PEMBELIAN
}

\author{
Marceilla \\ Program Studi Magister Manajemen Universitas Tarumanagara \\ estmarceilla@gmail.com
}

Masuk : 07-12-2019, revisi : 19-12-2019 diterima untuk diterbitkan : 19-12-2019

\begin{abstract}
This research aims to determine whether there is a effect with marketing mix to purchase satisfaction and whether it relates to marketing global product mix and local brands to purchase satisfaction by conducting a survey of 143 respondents using global and/or local lubricants brand. The independent variable used in this study is the marketing mix, namely product, price, place and promotion, while the dependent variable in this study is purchase satisfaction. This type of research is explanatory research with quantitative research. The location of the study was conducted at Jasmine Mansion Mansion Kemayoran, Jakarta. Data analysis techniques used descriptive analysis, regression analysis and comparative analysis by T-Test Independent using SPSS for Windows 25. The results of this study indicate product variables, prices, places and promotions related to purchases, both simultaneously and partially. From the results of comparative analysis shows there is no difference between product variables, price, place and promotion of global and local brand lubricant products to purchase satisfaction.
\end{abstract}

Keywords : Marketing Mix; Purchase Satisfaction; Global Brand; Local Brand; Product; Price; Place; Promotion

\begin{abstract}
Abstrak : Penelitian ini bertujuan untuk mengetahui apakah terdapat pengaruh bauran pemasaran terhadap kepuasan pembelian dan apakah terdapat perbedaan pengaruh bauran pemasaran produk pelumas merek global dan merek lokal terhadap kepuasan pembelian dengan melakukan survei terhadap 143 responden pengguna produk pelumas merek global dan lokal. Variabel independent yang digunakan dalam penelitian ini adalah bauran pemasaran, yakni product, price, place dan promotion, sedangkan variabel dependent dalam penelitian ini adalah kepuasan pembelian. Jenis penelitian ini adalah penelitian eksplanatori dengan pendekatan kuantitatif. Lokasi penelitian dilakukan di Apartment Mansion Jasmine Kemayoran, Jakarta. Teknik analisis data menggunakan analisis deskriptif, analisis regresi dan analisis komparatif T-Test Independent menggunakan SPSS for Windows 25. Adapun hasil dari penelitian ini menunjukan bahwa variabel product, price, place dan promotion memiliki pengaruh terhadap terhadap kepuasan pembelian, baik secara simultan maupun parsial. Dari hasil analisis komparatif menunjukan bahwa tidak terdapat perbedaan antara pengaruh variabel product, price, place dan promotion produk pelumas merek global dan merek lokal terhadap kepuasan pembelian.
\end{abstract}

Kata Kunci : Bauran Pemasaran; Kepuasan Pembelian; Global Brand; Local Brand; Produk; Harga; Distribusi; Promosi

\section{PENDAHULUAN}

Besarnya jumlah populasi penduduk yang dimiliki oleh Indonesia menjadikan Indonesia sebagai negara yang dilirik sebagai pasar yang sangat potensial bagi para pemasar produk, baik dari pemasar produk lokal maupun global dan mendorong terjadinya persaingan antara produk 
lokal dan produk global. Produk asing yang dipasarkan di Indonesia tersebut menjadi kompetitor bagi produk lokal yang diproduksi oleh perusahaan dalam negeri, seperti yang terjadi di industri pelumas beberapa tahun belakangan ini.

Industri pelumas merupakan industri strategis yang tumbuh cukup pesat di Indonesia dan berpotensi untuk terus tumbuh. Pesatnya pertumbuhan dari industri pelumas ini didorong oleh meningkatnya populasi kendaraan dan bergairahnya kegiatan industri yang dipercaya akan terus mendorong konsumsi produk pelumas ini. Kebutuhan produk pelumas di Indonesia pada tahun 2018 tercatat sebanyak 950 ribu kiloliter dimana hanya 75\% yang disuplai oleh produsen dalam negeri, padahal kapasitas terpasang produksi pelumas berdasarkan Lube Oil Blending Plant (LOBP) sebesar 1.8 juta kiloliter, namun baru termanfaatkan sebesar $40 \%$ atau sekitar 720 ribu kiloliter sehingga sisanya disuplai oleh pelumas impor dari luar negeri.

\section{TELAAH KEPUSTAKAAN}

\section{Kepuasan Pembelian}

Dalam proses pengambilan keputusan pembelian, konsumen yang merasa puas dengan produk atau jasa yang digunakan cenderung akan menyatakan hal - hal yang baik tentang produk atau jasa yang digunakannya tersebut kepada orang lain.

\section{Bauran Pemasaran}

Pengertian bauran pemasaran (marketing mix) menurut Kotler dan Keller yang diterjemahkan oleh Benyamin Molan (2012) adalah perangkat alat pemasaran yang digunakan perusahaan untuk mengejar tujuan pemasarannya.

Product. Menurut Kotler (2002) produk adalah segala seuatu yang dapat ditawarkan ke suatu pasar untuk memenuhi kebutuhan. Sebuah perusahaan harus senantiasa melakukan pengembangan dan perencanaan produk baru yang efektif.

Price. Harga adalah jumlah yang dibutuhkan untuk mendapatkan sejumlah kombinasi dari barang beserta pelayanannya (Swastha, 2002). Harga merupakan satu - satunya unsur dalam bauran pemasaran yang dapat memberikan pemasukan atau pendapatan bagi perusahaan.

Place. Kotler (2000) mengatakan bahwa distribusi mencakup segala kegiatan yang dilakukan perusahaan untuk membuat sebuah produk dapat diperoleh dan tersedia bagi konsumen sasaran.

Promotion. Menurut Kottler dan Armstrong (1999), promosi berarti aktivitas yang menyampaikan manfaat produk dan membujuk pelanggan untuk membeli. Sebaik apapun mutu produk, semenarik apapun atau seberapa besar manfaatnya, jika tidak ada orang yang mengetahui keberadaannya akan mustahil untuk dibeli.

\section{Kerangka Pemikiran}

Secara singkat, kerangka pemikiran yang menggambarkan hubungan antara variabel bebas (Product, Price, Place dan Promotion) dan variabel tak bebas (Kepuasan Pembelian) adalah sebagai berikut : 


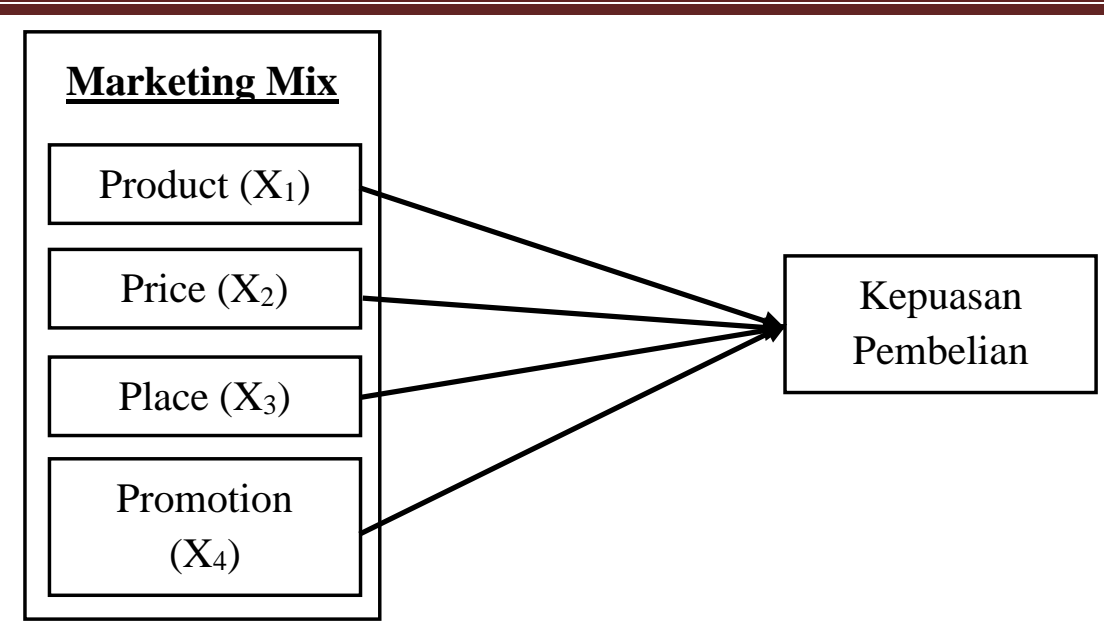

\section{Gambar 1 Kerangka Pemikiran}

\section{METODOLOGI PENELITIAN}

\section{Jenis Penelitian}

Jenis penelitian yang digunakan dalam penelitian ini adalah explanatory research dengan menggunakan pendekatan kuantitatif dengan menggunakan analisis deskriptif, regresi dan komparatif.

\section{Populasi dan Sampel Penelitian}

Dalam penelitian ini, populasi yang diambil sebagai bahan penelitian adalah para pengguna pelumas merek global atau lokal yang berdomisili di Apartment Mansion Jasmine Kemayoran, Jakarta dimana jumlah populasinya tidak dapat diketahui secara pasti. Mengingat jumlah populasi yang tidak diketahui secara pasti, maka penentuan jumlah sampel yang akan digunakan dalam penelitian ini dapat juga menggunakan rumus dari Rao Purba (1996).

$$
\begin{aligned}
& \mathrm{n}=\frac{\mathrm{Z}^{2}}{4(m o e)^{2}} \\
& \mathrm{n}=\frac{1.96^{2}}{4(0.1)^{2}} \\
& \mathrm{n}=96.04 \sim 100
\end{aligned}
$$

dimana $: \mathrm{n}=$ jumlah sampel; $\mathrm{Z}=$ tingkat kepercayaan, yakni $1.96 \%$; Moe $=$ margin of error, yakni 10\% sehingga, berdasarkan rumus diatas, dapat diperoleh jumlah sampel sebanyak 96,04 orang, namun dikarenakan adanya unsur pembulatan dan untuk mempermudah perhitungan, maka sampel yang diambil sebanyak min. 100 responden.

\section{Jenis Data dan Metode Pengambilan Data}

Dalam penelitian ini, metode pengumpulan data primer yang digunakan melalui kuesioner dengan menyebarkan pertanyaan secara acak (random) kepada 150 responden yang berdomisili di Apartment Mansion Jasmine Kemayoran, Jakarta. Dari 150 kuesioner yang telah disebar dan diisi oleh responden, didapatkan 143 responden yang kuesionernya valid, yakni yang lolos screening question.

\section{Metode Analisis Data}

Analisis Regresi. Untuk mengetahui apakah terdapat pengaruh secara parsial antara variabel bebas dan variabel tak bebas, dilakukan uji t. Sedangkan untuk mengetahui apakah semua 
variabel bebas memiliki pengaruh secara simultan terhadap variabel tak bebas, dilakukan uji F. Kedua uji tersebut menggunakan SPSS for Windows ver. 25 dengan tingkat signifikansi 0.05.

Analisis Komparatif. Uji komparatif atau T-Test Independent merupakan uji beda dua sampel berpasangan untuk mengetahui adakan perbedaan mean atau rata - rata yang bermakna antara 2 kelompok bebas yang berskala data interval atau rasio.

\section{ANALISIS DAN BAHASAN TEMUAN \\ Gambaran Umum Responden}

Pada penelitian ini, responden dideskripsikan berdasarkan jenis kelamin, usia, pekerjaan, pengeluaran per bulan dan produk pelumas yang digunakan. Berdasarkan jenis kelamin, dalam penelitian ini komposisinya hampir sama, yakni $48.95 \%$ berjenis kelamin laki - laki dan $51.05 \%$ berjenis kelamin perempuan. Dari seluruh responden, $39.86 \%$ memiliki pekerjaan sebagai pegawai swasta, 32.87\% memiliki pengeluaran sekitar Rp. 6,000,000 s.d Rp. 9,000,000 per bulan, dan $46.85 \%$ menggunakan produk pelumas merek lokal.

\section{Analisis Regresi}

Tabel 1

Hasil Analisa Regresi Linear Berganda

\begin{tabular}{|c|c|c|c|c|c|}
\hline \multirow[t]{2}{*}{ Model } & \multicolumn{2}{|c|}{$\begin{array}{l}\text { Unstandardized } \\
\text { Coefficients }\end{array}$} & \multirow{2}{*}{$\begin{array}{c}\text { Standardized } \\
\text { Coefficients } \\
\text { Beta }\end{array}$} & \multirow[t]{2}{*}{$\mathbf{t}$} & \multirow[t]{2}{*}{ Sig. } \\
\hline & B & Std. Error & & & \\
\hline (Constant) & 5.862 & 1.149 & & 5.103 & .000 \\
\hline Product & .125 & .067 & .156 & 1.867 & .064 \\
\hline Price & .139 & .065 & .180 & 2.131 & .035 \\
\hline Place & .141 & .061 & .185 & 2.307 & .023 \\
\hline Promotion & .164 & .059 & .229 & 2.762 & .007 \\
\hline $\mathrm{F}$ & 11.047 & & & & .000 \\
\hline $\mathrm{R}$ & .492 & & & & \\
\hline R Square & .243 & & & & \\
\hline
\end{tabular}

Dari data diatas dapat diinterpretasikan bahwa variabel price, place dan promotion memiliki pengaruh yang signifikan terhadap kepuasan pembelian, sedangkan variabel product tidak memiliki pengaruh yang signifikan terhadap kepuasan pembelian. Sedangkan untuk uji simultan $\mathrm{F}$, dapat dinyatakan bahwa product, price, place dan promotion secara simultan mempengaruhi kepuasan pembelian. 


\section{Analisis Komparatif}

Hasil uji komparatif T-Test Independent disajikan dalam tabel berikut ini :

\section{Tabel 2}

Hasil Analisa Komparatif T-Test Independent

\begin{tabular}{|c|c|c|c|c|c|c|c|}
\hline & \multicolumn{2}{|c|}{$\begin{array}{c}\text { Levene's Test for } \\
\text { Equality of Variances }\end{array}$} & \multicolumn{4}{|c|}{ t-test for Equality of Means } \\
\hline & & $\mathbf{F}$ & Sig. & $\mathbf{t}$ & df & $\begin{array}{l}\text { Sig. }(2- \\
\text { tailed) }\end{array}$ & Mean Diff \\
\hline \multirow{2}{*}{ Product } & $\begin{array}{l}\text { Equal variances } \\
\text { assumed }\end{array}$ & .043 & .836 & -.647 & 141 & .519 & -.1494 \\
\hline & $\begin{array}{l}\text { Equal variances } \\
\text { not assumed }\end{array}$ & & & -.646 & 136.712 & .519 & -.1494 \\
\hline \multirow{2}{*}{ Price } & $\begin{array}{l}\text { Equal variances } \\
\text { assumed }\end{array}$ & .323 & .571 & .397 & 141 & .692 & .0952 \\
\hline & $\begin{array}{c}\text { Equal variances } \\
\text { not assumed }\end{array}$ & & & .397 & 137.729 & .692 & .0952 \\
\hline \multirow{2}{*}{ Place } & $\begin{array}{c}\text { Equal variances } \\
\text { assumed }\end{array}$ & 1.010 & .317 & -1.413 & 141 & .160 & -.3420 \\
\hline & $\begin{array}{l}\text { Equal variances } \\
\text { not assumed }\end{array}$ & & & -1.408 & 135.625 & .161 & -.3420 \\
\hline \multirow{2}{*}{ Promotion } & $\begin{array}{l}\text { Equal variances } \\
\text { assumed }\end{array}$ & 5.332 & .022 & 1.077 & 141 & .283 & .2792 \\
\hline & $\begin{array}{c}\text { Equal variances } \\
\text { not assumed }\end{array}$ & & & 1.058 & 123.339 & .292 & .2792 \\
\hline
\end{tabular}

Sumber : Diolah oleh peneliti, 2019

Berdasarkan tabel diatas, nilai Sig. pada Levene'a Test for Equality of Variances lebih besar dari 0,05, sehingga dapat diartikan bahwa tidak terdapat perbedaan yang signifikan antara produk pelumas merek global dan produk pelumas merek lokal karena nilai Sig. (2-tailed) pada tabel diatas nilainya lebih bedar dari 0.05 .

\section{KESIMPULAN DAN SARAN}

\section{Kesimpulan}

Berdasarkan data yang telah diuraikan dalam hasil penelitian diatas, maka kesimpulan yang dapat ditarik adalah sebagai berikut :

1. Tidak terdapat perbedaan bauran pemasaran (product, price, place dan promotion) yang signifikan antara produk pelumas merek global dan produk pelumas merek lokal;

2. Variabel bebas bauran pemasaran (product, price, place dan promotion) secara simultan berpengaruh terhadap variabel tak bebas kepuasan pembelian;

3. Hanya variabel price, place dan promotion yang memiliki pengaruh terhadap kepuasan pembelian secara parsial.

\section{Saran}

Berdasarkan hasil penelitian dan pembahasan serta kesimpulan yang telah dikemukakan, agar produk pelumas merek lokal dapat memperkuat brand positioning-nya di pasar dalam negeri dengan mencari tahu kebutuhan pasar dan menanamkan awareness akan produk dan citra perusahaan di mata konsumen sehingga dapat menimbulkan confidence bagi konsumen untuk lebih memilih menggunakan produknya dibandingkan produk pelumas merek global, disamping produk pelumas lokal seharusnya lebih mengerti kebutuhan konsumen dibandingkan produk global yang menjadi pesaingnya. 


\section{DAFTAR PUSTAKA}

Badan Pusat Statistik. (2019). Berita Resmi Statistik Pertumbuhan Ekonomi Indonesia Triwulan IV-2018. https://www.bps.go.id/pressrelease/2019/02/06/1619/ekonomiindonesia-2018-tumbuh-5-17-persen.html.

Kotler, P., dan Armstrong, G. (1999). Prinsip-Prinsip Pemasaran. Jakarta : Erlangga.

Kotler, P., dan Keller, K. L. (2008). Manajemen Pemasaran. Edisi 12. Jakarta : PT. Indeks

Kotler, P. (1995). Manajemen Pemasaran. Jilid I. Jakarta : Salemba Empat

Kotler, P., dan Armstrong, G. (2008). Prinsip-Prinsip Pemasaran. Jilid I. Edisi keduabelas. Jakarta : Erlangga

Sugiyono. (2012).Metode Penelitian Kuantitatif, Kumulatif, (Cetakan Ke-17). Bandung : Alfabeta 